Esta obra forma parte del acervo de la Biblioteca Jurídica Virtual del Instituto de Investigaciones Jurídicas de la UNAM www.juridicas.unam.mx

\title{
PARIDAD: RUTA INCLUSIVA DE LAS MUJERES. LAS REFORMAS POLÍTICO-ELECTORALES 2014
}

\author{
María del Pilar HeRnÁNDEZ
}

La real igualdad de oportunidades no existe sólo porque las barreras formales se eliminen. La discriminación directa y las barreras ocultas impiden que las mujeres obtengan su parte de influencia política. ${ }^{2}$

\section{Sumario:}

I. Consideraciones preliminares

II. Un marco clave: institucionalismo electoral; un concepto imprescindible: derechos políticos

III. Reconocimiento normativo de los derechos de las mujeres y partidos políticos

IV. ¿Y los partidos políticos?

V. Tutela jurisdiccional efectiva de los derechos políticos de las mujeres: la jurisdicción federal

VI. La reforma 2014 y la ruta inclusiva de las mujeres

VII. Fuentes consultadas.

\section{CONSIDERACIONES PRELIMINARES}

El ejercicio de los derechos políticos-electorales de hombres y mujeres en la región latinoamericana es un tema que aún no termina, su naturaleza multifactorial y multidimensional presenta avances y regresiones que van más allá de los esfuerzos por generar, primero, mecanismos que hagan posible la igualdad progresiva en la diversidad

\footnotetext{
${ }^{1}$ Investigadora del Instituto de Investigaciones Jurídicas, Universidad Nacional Autónoma de México, correo electrónico: mphm@unam.mx. Trabajo entregado como capítulo de libro: "Reforma político-electoral 2014: reflexiones” a publicar por el Instituto Electoral Veracruzano, 14 de octubre 2014.

${ }^{2}$ Acerca de las cuotas, QuotaProject. Base de datos global de cuotas de mujeres, IDEA-Universidad de Estocolmo-Unión Interlamentaria-Para la democracia. Para todo el mundo, http://www.quotaproject.org/es/aboutQuotas.cfm
} 
Esta obra forma parte del acervo de la Biblioteca Jurídica Virtual del Instituto de Investigaciones Jurídicas de la UNAM

humana que históricamente nos ha signado y, segundo, la visibilización y resignificación de las mujeres en el acceso, goce, ejercicio y tutela jurisdiccional efectiva de derechos políticos-electorales.

Decimos que el problema del acceso al pleno ejercicio de los derechos políticos de las mujeres se agrava de cara a las viejas y nuevas condiciones que México presenta, como: la situación de pobreza que conlleva a la atención prioritaria de necesidades básicas, los rezagos socioculturales, educativos y de salud de la población indígena femenina, su inserción cada vez mayor en una estructura laboral poco dignificante que, absorbe y no abona en su ciudadanización, la escasa atención a fenómenos viejos de diversa naturaleza pero con rostro de actualidad (desplazamiento interno por violencia generada por la delincuencia organizada, desastres naturales, obras públicas, inter alia) que inciden de manera específica en una eventual reivindicación de un estatuto político eficientemente participativo, entre otras. Nada ajeno a quienes desde el PNUD han focalizado los fenómenos en América Latina.

Es innegable que el Estado mexicano en aras de su propia legitimidad y virtud con la reivindicación de los derechos políticos en la cabeza de diversos grupos de interés y de presión tuvo que transitar a la construcción de un "nuevo andamiaje institucional", que posibilitara la apertura democrática desde la misma institucionalidad, generando una especie de cambio atenuado de un partidismo monolítico y hegemónico a un sistema multipartidista, esto es, la constitucionalización de los partidos políticos y la instauración de un sistema electoral mixto (mayoría relativa y representación proporcional) con predominante mayoritario: una arena de contienda plural ideológica y estructuralmente diferenciada a finales de los años 70's, puntualmente en 1977, que se dio en llamar la gran reforma política electoral "Reyes Heroles".

Después de 15 años surge la emergencia de nuevas instituciones (un Instituto y un Tribunal —de índole electoral- en la ola de los órganos autónomos) y reglas que oxigenaron aún más, virtud de los vientos de la transición democrática, espacios en que, paulatinamente, nuevos actores (mujeres, después jóvenes e indígenas, todos signados con un sistema de cuotas) adquirirán un rostro definido pero indefectiblemente condenados a ser cooptados por aquellos que buscaban legitimar la democracia mexicana y que hoy muestran los claros signos de una clase privilegiada que sólo observa una ley: la de hierro de las oligarquías. 
Esta obra forma parte del acervo de la Biblioteca Jurídica Virtual del Instituto de Investigaciones Jurídicas de la UNAM www.juridicas.unam.mx

Hablar entonces de institucionalismo político, específicamente electoral, hace necesaria la apelación a un contenido con contornos definidos que permitan dimensionar, en prospectiva, lo que se avecina en México en las próximas elecciones, dos son de carácter federal (renovación de la titularidad del Ejecutivo federal, senadores y diputados del Congreso General), diez de carácter estadual y municipal, por lo que, en total son doce elecciones concurrentes a celebrarse el primer domingo del mes de julio.

\section{UN MARCO CLAVE: INSTITUCIONALISMO ELECTORAL; UN CONCEPTO IMPRESCINDIBLE: DERECHOS POLÍTICOS}

El estudio de las instituciones como reglas formales e informales es de vital relevancia para estudiar los contextos latinoamericanos. Guillermo O'Donnell ${ }^{3}$ destaca la importancia de estudiar las reglas informales en los escenarios políticos de América Latina. Para O'Donnell la "democracia" en América Latina son "democracias delegativas", en donde los controles institucionales para vigilar el quehacer de los políticos son débiles. A contracorriente de la literatura politológica institucionalista de rational choice sobre América Latina, ${ }^{4}$ O'Donnell pone el acento en una perspectiva más de sociología política, en donde la institucionalidad se concibe también en marcos de reglas informales. En esta línea de O'Donnell, las investigaciones empíricas de Steven Levitsky y Leandro Wolfson se enfocan a estudiar las reglas tanto formales como informales de la política. El trabajo clave de Levitsky y Wolfson ${ }^{5}$ en su estudio titulado Del sindicalismo al clientelismo: Ia transformación de los vínculos partido-sindicatos en el peronismo, 1983-1999 (2004). A estos trabajos se suma la obra de Gisela Zaremberg titulado Mujeres, votos y asistencia social en el México priísta y la Argentina peronista. ${ }^{6}$ Estas dos últimas investigaciones son en parte respuesta a las investigaciones institucionalistas de la teoría de la elección racional que se inscriben en el estudio de la democracia en América Latina.

Confirmamos lo que O’Donnell expresara en el ya lejano 1996 a la luz de los

3 O’Donnell, Guillermo, “Delegative democracy”, Journal of Democracy, núm. 1, enero de 1994, pp. 55-69.

${ }^{4}$ Munck, Gerardo L., "La política democrática en América Latina, contribuciones de una perspectiva institucional”, Política y Gobierno, México, núm. 2, 2004, pp. 315-346.

${ }^{5}$ Levitsky, Steven y Wolfson, Leandro, "Del sindicalismo al clientelismo. La transformación de los vínculos partidosindicatos en el peronismo, 1983-1999”, Desarrollo Económico, vol. 44, núm. 173, junio, pp. 3-32.

${ }^{6}$ Zaremberg, Gisela, Mujeres, votos y asistencia social en el México priista y la Argentina peronista, México, Flacso, 2009. 
Esta obra forma parte del acervo de la Biblioteca Jurídica Virtual del Instituto de Investigaciones Jurídicas de la UNAM www.juridicas.unam. $\mathrm{mx}$

DOl: http://dx.doi.org/10.22201/iij.24487910e_2015.7.10087

elementos definitorios de las poliarquías, a saber:

1. Autoridades públicas electas;

2. Elecciones libres y limpias;

3. Sufragio universal;

4. Derecho a competir por cargos públicos;

5. Libertad de expresión;

6. Información alternativa; y,

7. Libertad de asociación.

México es una poliarquía institucionalizada informalmente, por lo que, recobro las líneas de O’Donnell:

Los atributos del 1 al 4 nos dicen que un aspecto básico de la poliarquía es que las elecciones son incluyentes, limpias y competitivas. Del 5 al 7 se refieren a las libertades políticas y sociales mínimamente necesarias, no sólo durante los comicios sino también entre ellos, para que las elecciones sean limpias y competitivas. De acuerdo con estos criterios, algunos países de América Latina no son poliarquías en la actualidad: ... y México celebraron elecciones pero se vieron afectadas por serias irregularidades antes, durante y después de la votación.

Desde las reflexiones teóricas de la calidad de la democracia y construcción de la ciudadanía, la situación en términos de avance sustantivo de los derechos políticos electorales de las ciudadanas mexicanas y de las instituciones a cargo de rendir eficacia en las normas ya instituidas, lejos están de asumir las esferas de los derechos civiles, políticos, sociales y culturales y transitar, así, de la democracia electoral a la democracia de ciudadanía.

Los elementos denotativos de la poliarquía sólo son concebibles a la luz de la categoría de los derechos políticos, que los denotamos como aquellos que posibilitan la participación de quienes tienen y rinden eficaz la calidad de ciudadanos en la conformación de la voluntad general del Estado, id est, los derechos a participar en el ejercicio del poder político a través del voto y el derecho a ser elegido (acotamiento sólo a estos derechos que realiza Marshall) y que, inopinadamente, también comprende otras situaciones extensivamente tuteladas como lo son: ejercicio y goce del sufragio en elecciones directas (plebiscito, referéndum y/o revocación del mandato); libertades 
Esta obra forma parte del acervo de la Biblioteca Jurídica Virtual del Instituto de Investigaciones Jurídicas de la UNAM www.juridicas.unam.mx

públicas de, expresión y acceso a la información, asociación, reunión, manifestación en asuntos públicos, petición, derecho a ocupar cargos de designación y derecho a la tutela jurisdiccional efectiva (implicativa ésta del derecho al acceso a la justicia sin elementos obstáculos procesales que lo impidan y mediante un recurso eficaz; obtener una sentencia de fondo debidamente fundada y motivada en un tiempo razonable; que la sentencia se cumpla —ejecutoriedad del fallo - todo ello mediante recursos eficaces).

En el marco del presente seminario, analizaremos el avance de los derechos políticos electorales de género a través de los partidos políticos, así como los actores principales para el ejercicio de la representación política de las mujeres, la acción de los órganos electorales de la jurisdicción federal electoral para rendir eficaces esos derechos.

\section{RECONOCIMIENTO NORMATIVO DE LOS DERECHOS DE LAS MUJERES Y PARTIDOS POLÍTICOS}

El actual esquema de los derechos políticos electorales de las mujeres se determina en tres tipos de normas: constitucionales, legales y reglamentarias.

1. A nivel constitucional, el catálogo de derechos se mantiene igual que en 1953, esto es, en 58 años normativamente el catálogo especificamente consagrado en los artículos 35 y 36 no ha sufrido cambios, sólo en lo que hace a la reivindicación del derecho a la igualdad formal entre hombres y mujeres (artículo 40., párrafo primero), ${ }^{7}$ así como de los derechos de las mujeres indígenas a participar en la elección de sus representantes y a ser electas "en condiciones de equidad frente a los varones..." es lo encomiable (artículo 20.,). ${ }^{8}$

Formalmente el artículo 34 nos reconoce el estatus de ciudadanas y, en consecuencia a los titulares de los derechos políticos del artículo 35, precepto que decimonónicamente mantiene, inexplicablemente y pese al sin número de modificaciones que ha sufrido el texto constitucional, la expresión de prerrogativas. Se suman al anterior los prescritos en el artículo 36 en términos de obligaciones que, contrario sensu implican derechos, los siguientes:

a. Votar y ser votadas;

\footnotetext{
${ }^{7}$ Diario Oficial de la Federación del 31 de diciembre de 1974.

${ }^{8}$ Diario Oficial de la Federación del 14 de enero de 2001.
} 
Esta obra forma parte del acervo de la Biblioteca Jurídica Virtual del Instituto de Investigaciones Jurídicas de la UNAM

b. Ser nombradas para cualquier empleo o comisión, cumpliendo las calidades que establezcan las leyes;

c. De asociación política;

d. Tomar las armas en el Ejército o Guardia Nacional, para la defensa de la República y de sus instituciones;

e. Derecho de petición;

f. Inscripción en el catastro de la municipalidad y en el Registro Nacional de Ciudadanos;

g. Desempeñar los cargos concejiles del municipio donde se resida, las funciones electorales y las de jurado.

El 13 de diciembre de 2013 el Senado de la República aprobó las reformas constitucionales que integran la denominada reforma política-electoral del presidente Peña Nieto, quien las promulgara el 31 de enero del presente 2014, estas reformas son importantes virtud la prescripción contenida en el artículo 41, base I, segundo párrafo en donde se consagra "...garantizar la paridad entre los géneros, en candidaturas a legisladores federales y locales...".

Tal reconocimiento trasciende en la exigibilidad de los derechos político-electorales de las mujeres, administrativa y jurisdiccionalmente ante los órganos electorales competentes en términos de equidad y paridad, así se salva la omisión cometida en 2007, ya que entonces en los artículos 35 y 36, ya indicados, no se hacía expresión alguna de dichos términos, aspecto que en las reformas constitucionales de 2007 tampoco fueron reivindicadas en el artículo 41 que condensa, esencialmente, el fundamento de la regulación de los partidos políticos y de la autoridad administrativa electoral. Menos aún se hizo referencia al artículo 99 tratándose de la competencia del órgano jurisdiccional electoral. Ni qué decir de los intocados artículos 115 y 116 que prescriben las bases constitucionales de la organización de los municipios y las entidades federativas. Sólo se hace alusión tangencial a la equidad en el artículo 134 de la responsabilidad de los servidores públicos (federales, estatales, municipales y del Distrito Federal) en caso de no observarla en la competencia de los partidos políticos.

2. Las cuotas de género, sin lugar a dudas, son hasta que entren en vigor las reformas 2013, un mecanismo legal que ha permitido asegurar un umbral mínimo de representatividad del género femenino, esencialmente en los órganos legislativos. 
Esta obra forma parte del acervo de la Biblioteca Jurídica Virtual del Instituto de Investigaciones Jurídicas de la UNAM www.juridicas.unam.mx

Quedaron atrás los primeros escarceos con las cuotas de género y la paridad que incidentalmente se consagraron en el artículo 175 del Código Federal de Instituciones y Procedimientos Electorales de 1993, ${ }^{9}$ así como el reconocimiento expreso de $1996^{10}$ pasando por la memorable reforma de $2002^{11}$ que, personalmente, consideramos presentó una sola falencia: liberó las cuotas a los partidos políticos tratándose de candidaturas de mayoría relativa, resultado de "procesos de elección mediante voto directo". Expresión abierta sin mecanismo o procedimiento claro que definiera tal elección.

A la sazón de las reformas constitucionales en materia electoral que se verificaron en $2007,{ }^{12}$ en el $2008^{13}$ se expidió un nuevo Cofipe que se erige en el referente más actual de la legislación electoral en materia de cuotas y equidad de género. Por lo cual, los aspectos relevantes y que se enderezan a las obligaciones de los partidos políticos son:

\section{a) Deberán observar la igualdad de oportunidades y la equidad entre los hombres y}

\footnotetext{
${ }^{9}$ En su numeral 3 del artículo 175 se establecía: "los partidos políticos, promoverán en los términos que determinen sus documentos internos, una mayor participación de las mujeres en la vida política del país, a través de su postulación a cargos de elección popular".

${ }^{10}$ Fracción XXII, transitoria del artículo 5o., del Cofipe: “los partidos políticos nacionales considerarán en sus estatutos que las candidaturas a diputados y senadores no excedan el 70 por ciento para un mismo género. Asimismo promoverán la mayor participación de las mujeres".

${ }^{11}$ Artículo 175, apartado A. De la totalidad de las solicitudes de registro, tanto diputados como senadores que presenten los partidos políticos o las coaliciones ante el IFE, en ningún caso incluirán más del 70\% de candidatos propietarios de un mismo género."
}

Artículo 175, apartado B. De la lista de representación proporcional se integrarán por segmentos de tres candidaturas. En cada uno de los tres primeros segmentos de cada lista habrá una candidatura de género distinto. Lo anterior sin perjuicio de lo que señale la normatividad interna y el procedimiento de cada partido político.

Por su parte el artículo 175, apartado C, disponía una serie de medidas dirigidas a los partidos políticos con la finalidad de rendir eficaces las disposiciones de los dos preceptos precedentes, por lo que hecho el cierre de candidaturas el Consejo General del IFE podía requerir a un partido político o coalición para que en el plazo de 48 horas, contadas a partir de la notificación, rectificara la solicitud de registro, apercibiéndole que de no hacerlo procedía la amonestación pública. En caso de reincidencia procedía la negativa del registro de las candidaturas; como hasta ahora ocurre, se exceptúan las candidaturas de mayoría relativa resultado de la elección mediante voto directo, esto es así bajo el principio de la conservación de los actos válidamente celebrados.

${ }^{12}$ Diario Oficial de la Federación del 13 de noviembre de 2007.

${ }^{13}$ Diario Oficial de la Federación del 14 de enero de 2008. 
Esta obra forma parte del acervo de la Biblioteca Jurídica Virtual del Instituto de Investigaciones Jurídicas de la UNAM

mujeres para tener acceso a cargos de elección popular, incluidos en su declaración de principios y en sus órganos de dirigencia así como en el registro de candidatos (artículos 40., in fine, 25.1, inciso e), 38.1, inciso s) y 218.3);

b) Registrar candidatos a diputados y senadores por los principios de mayoría relativa y representación proporcional, en fórmulas compuestas por propietario y suplente, considerándose fórmulas y candidatos por separado, salvo para efectos de la votación (artículo 218);

c) Se eleva la cuota "al menos al $40 \%$ de candidatos propietarios de un mismo género, procurando la paridad" (artículo 219);

d) Las listas plurinominales deberán contener al menos dos mujeres en cada segmento de cinco candidatos de manera alternada (artículo 220.1);

e) Se siguen exceptuando de la cuota de género “las candidaturas de mayoría relativa que sean resultado de un proceso de elección democrático, conforme a los estatutos de cada partido" (artículo 219);

f) Se autoriza la sustitución de candidatos, las condiciones y plazos de procedencia (artículo 227);

g) Se prescribe como infracción el incumplimiento del principio de imparcialidad previsto en el artículo 134 de la Constitución federal, cuando la conducta afecte la equidad de la competencia de los partidos políticos, entre los aspirantes, precandidatos o candidatos durante los procesos electorales, haciendo imputables a las autoridades o servidores públicos de los poderes de la Unión, entidades federativas, municipios, Distrito Federal u órganos autónomos (artículo 237);

h) De manera inédita se dispone en el artículo 78.1, apartado V, que los partidos políticos deberán de destinar el $2 \%$ de su financiamiento público anualmente para “capacitación, promoción y desarrollo de liderazgo político de las mujeres".

La puesta en marcha del nuevo porcentaje de cuotas ha tenido lugar en las elecciones legislativas federales realizadas en el 2009, a través de las cuales se eligieron a las diputadas y los diputados de la LXI Legislatura. Tratándose de los senadores y las medidas prescritas para fortalecer el liderazgo de las mujeres evidenciaron sus resultados en las elecciones 2012, tratándose de mujeres electas, 36.8\% (184 de 500) en 
Esta obra forma parte del acervo de la Biblioteca Jurídica Virtual del Instituto de Investigaciones Jurídicas de la UNAM www.juridicas.unam. $\mathrm{mx}$

DOI: http://dx.doi.org/10.22201/iij.24487910e.2015.7.10087

la Cámara de Diputados y en el Senado, 33\% (42 de 128). ${ }^{14}$

Por lo que hace al $2 \%$ para fomentar la capacitación y liderazgo de las mujeres es de referir que a partir de 2008, el Instituto Federal Electoral ha realizado "puntualmente" su labor de fiscalización con la finalidad de evitar una nueva forma de elusión electoral que perjudica la inclusión de las mujeres y la plena consolidación de una ciudadanía de género, mediante la aprobación del Reglamento para la Fiscalización de los Recursos de los Partidos Políticos Nacionales" ${ }^{15}$ y que de conformidad con su artículo primero transitorio entró en vigor el 1 de enero de 2009, con excepción de las obligaciones relativas a la presentación de los informes trimestrales; el registro y comprobación de los gastos relacionados con el desarrollo de las actividades específicas a que se refiere el inciso c) del artículo 36, del Código Federal de Instituciones y Procedimientos Electorales; la comprobación y registro de los gastos destinados a la capacitación, promoción y desarrollo del liderazgo político de las mujeres; así como la comprobación y registro de los ingresos y egresos relacionados con las precampañas, las cuales surtieron efectos a partir de su aprobación por el Consejo General del Instituto Federal Electoral.

No obstante, la diligente actuación del IFE, tal como lo ha reconocido su entonces presidente, de 2008 a 2011, los partidos han gastado en ese rubro 224 millones 734 mil 20 pesos.

Montos correspondientes por partido político desde 2008 hasta $2011^{16}$

\footnotetext{
${ }^{14}$ Si bien, a la luz de la actual conformación de la Cámara de Diputados, resultado de la aplicación de las medidas antes enunciadas, es posible advertir un pequeño avance en términos del aumento en el número de mujeres legisladoras, que no alcanza siquiera a cubrir el piso mínimo de 30\% (que finalmente volvió a quedar en 27.6\%, en razón de la solicitud de licencia de legisladoras a favor de familiares u otros personajes de sus partidos — PRI, PRD, PVEM y PT—) recomendado en el ámbito internacional; a lo anterior se suma que ninguno de los principales partidos políticos presenta en su grupo parlamentario la cuota mínima de $40 \%$ de mujeres legisladoras, tal como se observa más adelante en este estudio. Sin embargo, la cifra es de considerarse ya que supera lo obtenido en la LIX Legislatura (2003-2006) puesto que fue de $27.6 \%$.

${ }^{15}$ Diario Oficial de la Federación del 8 de septiembre de 2008.

${ }^{16}$ Género y Democracia, México, IFE, 2011, http://genero.ife.org.mx/genero_partidos.html
} 
Esta obra forma parte del acervo de la Biblioteca Jurídica Virtual del Instituto de Investigaciones Jurídicas de la UNAM www.juridicas.unam. $m x$

$2 \%$ destinado al desarrollo del liderazgo politico de las mujeres (por Partido)

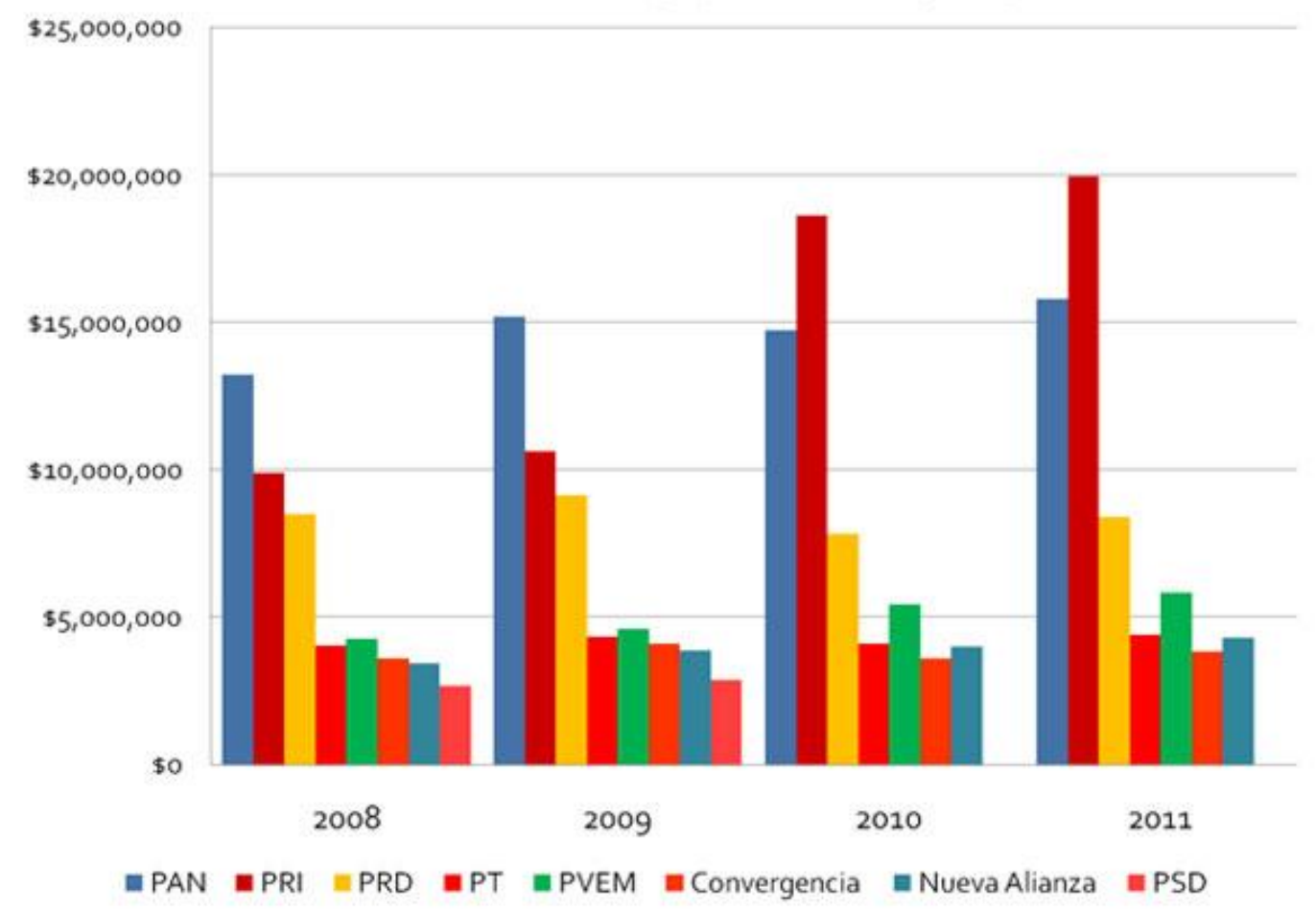

Desglose por cantidades

\begin{tabular}{|c|c|c|c|c|}
\hline Partido & 2008 & 2009 & 2010 & 2011 \\
\hline & $13,219,765$ & $15,187,263$ & $14,711,119$ & $15,769,162$ \\
\hline Dólares & $1,101,647$ & $1,265,605$ & $1,225,927$ & $1,314,097$ \\
\hline & $9,873,825$ & $10,624,718$ & $18,606,721$ & $19,944,941$ \\
\hline Dólares & 822,819 & 885,393 & $1,550,560$ & $1,662,078$ \\
\hline $\begin{array}{l}\text { 淡急 } \\
\text { PRD }\end{array}$ & $8,484,198$ & $9,129,411$ & $7,818,010$ & $8,380,291$ \\
\hline Dólares & 707,017 & 760,784 & 651,501 & 698,358 \\
\hline & $4,024,239$ & $4,330,278$ & $4,089,973$ & $4,384,129$ \\
\hline
\end{tabular}

DR (C) 2018. Instituto de Investigaciones Jurídicas, UNAM, 
Esta obra forma parte del acervo de la Biblioteca Jurídica Virtual del Instituto de Investigaciones Jurídicas de la UNAM www.juridicas.unam. $m x$

DOl: http://dx.doi.org/10.22201/iij.24487910e_2015.7.10087

\begin{tabular}{|c|c|c|c|c|}
\hline Dólares & 335,353 & 360,856 & 340,831 & 365,344 \\
\hline$\underset{U 1}{2}=$ & $4,249,573$ & $4,572,748$ & $5,420,152$ & $5,809,976$ \\
\hline \multirow[t]{2}{*}{ Dólares } & 354,131 & 381,062 & 451,679 & 484,165 \\
\hline & $3,588,987$ & $4,097,255$ & $3,569,177$ & $3,825,877$ \\
\hline Dólares & 299,082 & 341,438 & 297,431 & 318,823 \\
\hline ALIANZEA & $3,417,897$ & $3,837,273$ & $3,985,992$ & $4,272,669$ \\
\hline Dólares & 284,825 & 319,773 & 332,166 & 356,056 \\
\hline 世ै/ & $2,654,758$ & $2,856,647$ & $n / a^{*}$ & n/a* \\
\hline Dólares & 221,230 & 238,054 & $n / a^{*}$ & $\mathrm{n} / \mathrm{a}^{*}$ \\
\hline Total pesos & $49,513,242$ & $54,635,591$ & $58,201,142$ & $62,387,045$ \\
\hline Total dólares & $4,126,104$ & $4,552,966$ & $4,850,095$ & $5,198,920$ \\
\hline \multicolumn{5}{|c|}{$\begin{array}{l}\text { Nota: las cantidades están expresadas en pesos mexicanos en la primera fila de datos } \\
\text { y en la segunda se expresan en dólares americanos, el tipo de cambio es de } \$ 12 \text { pesos }\end{array}$} \\
\hline
\end{tabular}

En julio de 2011 el Consejo General del IFE aprobó las modificaciones al Reglamento de Fiscalización, ${ }^{17}$ en ellas se integran puntualizaciones en referencia al uso del $2 \%$ de gasto ordinario para la capacitación, promoción y desarrollo del liderazgo político de las mujeres. Las modificaciones definen, a través de conceptos de perspectiva de equidad de género las actividades, los programas y contenidos, así como las precisiones y evidencias que los partidos políticos deben presentar al reportar los gastos.

\footnotetext{
${ }^{17}$ Diario Oficial de la Federación del 7 de julio de 2011.
} 
Esta obra forma parte del acervo de la Biblioteca Jurídica Virtual del Instituto de Investigaciones Jurídicas de la UNAM

En estricto sentido se determina que el $2 \%$ del financiamiento anual deberá ser afectado puntualmente para la capacitación, promoción y desarrollo del liderazgo político de las mujeres con un enfoque de equidad (artículo 221), así como de la investigación, análisis, diagnóstico, estudios comparados, divulgación y difusión (artículo 284).

Se determina que los partidos políticos dentro de los 30 días siguientes a la aprobación del financiamiento público, para actividades ordinarias permanentes por parte del Consejo General del IFE, deberán presentar un programa de gastos para el desarrollo de las actividades específicas y otros gastos (artículo 286).

Conforme al numeral 2 del propio artículo 286 se prescribe que los programas de gasto para la capacitación, promoción y desarrollo del liderazgo político de las mujeres deberán retomar los elementos siguientes:

a) Acciones afirmativas: medidas temporales cuyo fin es acelerar la participación en condiciones de igualdad de la mujer en el ámbito político, económico, social, cultural y civil, o en cualquier otro ámbito. El Comité contra todas las formas de Discriminación contra la Mujer (CEDAW) en su Recomendación General 25, considera la aplicación de estas medidas no como excepción a la regla de no discriminación sino como parte de una estrategia necesaria para lograr la igualdad sustantiva de la mujer y el hombre en el goce de sus derechos humanos y libertades fundamentales;

b) Adelanto de las mujeres: disminución de las brechas de desigualdad entre mujeres y hombres para garantizar el pleno reconocimiento, goce y ejercicio de sus derechos con base en la igualdad sustantiva como política del Estado;

c) Empoderamiento de las mujeres: proceso por medio del cual las mujeres transitan de cualquier situación de opresión, desigualdad, discriminación, explotación o exclusión a un estadio de conciencia-autodeterminación y autonomía, en el que se manifiesta el ejercicio del poder democrático que emana del goce pleno de sus derechos y libertades;

d) Igualdad sustantiva: supone la modificación de las circunstancias que impiden a las personas el ejercicio pleno de los derechos y el acceso a las oportunidades a través de medidas estructurales, legales o de política pública;

e) Liderazgo político de las mujeres: capacidades de las mujeres para influir en la esfera pública con pleno ejercicio de sus derechos en el ámbito político. 
Esta obra forma parte del acervo de la Biblioteca Jurídica Virtual del Instituto de Investigaciones Jurídicas de la UNAM

Al desarrollo del liderazgo político se debe entender a la evolución progresiva de la condición de las mujeres para potenciar su liderazgo político en los espacios públicos de toma de decisión.

Asimismo, por promoción del liderazgo político se debe entender al impulso de acciones afirmativas que permiten alcanzar el efectivo liderazgo político de las mujeres; $y$,

f) Perspectiva de género: permite visibilizar la asignación social diferenciada de roles y tareas en virtud del sexo; revela las diferencias en oportunidades y derechos que siguen a esta asignación; evidencia las relaciones de poder originadas en estas diferencias, y pregunta por los impactos diferenciados de las leyes y políticas públicas basadas en estas asignaciones, diferencias y relaciones de poder.

Por su parte el artículo 287, último párrafo, clarifica a los partidos políticos de lo que habrán de entender por capacitación, así como el programa de enseñanza-aprendizaje que los partidos políticos deben implementar para mejorar y ampliar los conocimientos, habilidades y aptitudes que fomenten los liderazgos políticos y el empoderamiento de las mujeres, a fin de lograr su inclusión en la toma de decisiones en condiciones de igualdad con los hombres. El diverso artículo 288.1.b, puntualiza que la capacitación, promoción y el desarrollo del liderazgo político de las mujeres contendrán información, valores, concepciones y actitudes orientadas a propiciar la igualdad de oportunidades para el desarrollo político, en el acceso al poder público y la participación en los procesos de toma de decisiones. Asimismo, deberán desarrollarse en el territorio que comprende los Estados Unidos Mexicanos, procurando beneficiar al mayor número de mujeres.

En el rubro de capacitación y formación para el liderazgo político de la mujer se comprende una serie de actividades como las conferencias, seminarios, entre otros, que favorezcan el desarrollo de conocimientos, habilidades y actitudes, en temas diversos (artículo 293) que, desde nuestra óptica en nada abonan a la ciudadanización de género.

Para evitar la distracción de recursos no se considerarán gastos programados aquellos de carácter operativos y servicios personales generales de las secretarías de la mujer de los propios partidos u órganos equivalentes, cuando no se encuentren relacionados de manera directa y exclusiva con las actividades específicas y el correspondiente a la capacitación, promoción y el desarrollo del liderazgo político de las 
Esta obra forma parte del acervo de la Biblioteca Jurídica Virtual del Instituto de Investigaciones Jurídicas de la UNAM www.juridicas.unam.mx

mujeres.

Esperaremos a que el nuevo reglamento sea aplicado y el Consejo General del IFE rinda el correspondiente informe 2012 para verificar el cumplimiento del mismo.

\section{IV. ¿Y LOS PARTIDOS POLÍTICOS?}

Conforme a las cifras que arroja la Lista Nominal de Electores 2012, las mujeres en términos absolutos representamos de un total de 79 millones, 454 mil, 815 mexicanos, el $51.85 \%(41,194,578)$ de cara al $48.15^{18}$ de los hombres $(38,260,235)$, sociológica y políticamente estamos subrepresentadas, no obstante, en casi la misma proporción generamos el mayor porcentaje.

Conforme al cohorte de edad y sexo se aprecia que la participación de las mujeres es siempre superior a la de los hombres desde los 18 años hasta el grupo de 45-49 años.

Cuantitativamente los partidos políticos nacionales presentan los siguientes números de afiladas: ${ }^{19}$

Afiliados a los partidos politicos porcentajes relativos mujeres-hombres

\begin{tabular}{|l|l|l|l|}
\hline \multirow{2}{*}{ Partido político } & \multicolumn{1}{|c|}{$\begin{array}{c}\text { Total } \\
\text { afiliados(as) } \\
\text { términos absolutos } \\
\text { millones }\end{array}$} & $\begin{array}{l}\text { Mujeres afiliadas } \\
\text { términos relativos }\end{array}$ & $\begin{array}{l}\text { Hombres afiliados } \\
\text { términos relativos }\end{array}$ \\
\hline $\begin{array}{l}\text { CONVERGENCIA } \\
\text { NARTIDO ACCIÓN }\end{array}$ & 136756 & $5674 \%$ & $43.26 \%$ \\
\hline $\begin{array}{l}\text { PARTIDO NUL (PAN) } \\
\text { ALIANZA (PANAL) }\end{array}$ & 1314901 & $47 \%$ & $53 \%$ \\
\hline
\end{tabular}

${ }^{18}$ http://listanominal.ife.org.mx/consulta_permanente_ln.htm, Instituto Federal Electoral, 2012.

${ }^{19}$ Cifras consultadas en el sitio de GEPALL: Género y Partidos Políticos en América Latina, Banco Interamericano de Desarrollo,http://www6.iadb.org/Research/Geppal/tabsdataParty.cfm?language $=$ Spanish\&country=MEX\&parties $=57 \& c$ ategory=1\&pagref $=1$ 
Esta obra forma parte del acervo de la Biblioteca Jurídica Virtual del Instituto de Investigaciones Jurídicas de la UNAM www.juridicas.unam.mx

DOI: http://dx.doi.org/10.22201/iij_.24487910e_2015.7.10087

\begin{tabular}{|l|l|l|l|}
\hline $\begin{array}{l}\text { PARTIDO VERDE } \\
\text { ECOLOGÍSTA } \\
\text { (PVEM) }\end{array}$ & 359901 & $18.18 \%$ & $81.82 \%$ \\
\hline $\begin{array}{l}\text { PARTIDO DE LA } \\
\text { REVOLUCIÓN } \\
\text { DEMOCRÁTICA } \\
\text { (PRD) }\end{array}$ & 1795851 & $64 \%$ & $36 \%$ \\
\hline $\begin{array}{l}\text { PARTIDO } \\
\text { REVOLUCIONARIO } \\
\text { INSTITUCIONAL } \\
\text { (PRI) }\end{array}$ & SIN DATOS & SIN DATOS & SIN DATOS \\
\hline $\begin{array}{l}\text { PARTIDO DEL } \\
\text { TRABAJO (PT) }\end{array}$ & SIN DATOS & SIN DATOS & SIN DATOS \\
\hline
\end{tabular}

Inclusión de mujeres en cargos de dirigencia partidaria

Máximo órgano ejecutivo

\begin{tabular}{|l|l|}
\hline Partido político & Términos relativos \\
\hline CONVERGENCIA & $14.81 \%$ \\
\hline PARTIDO ACCIÓN NACIONAL (PAN) & $11.76 \%$ \\
\hline PARTIDO NUEVA ALIANZA (PANAL) & $11.76 \%$ \\
\hline PARTIDO VERDE ECOLOGÍSTA (PVEM) & $11.00 \%$ \\
\hline $\begin{array}{l}\text { PARTIDO DE LA REVOLUCIÓN } \\
\text { DEMOCRÁTICA (PRD) }\end{array}$ & $50 \%$ \\
\hline $\begin{array}{l}\text { PARTIDO REVOLUCIONARIO } \\
\text { INSTITUCIONAL (PRI) }\end{array}$ & $22.22 \%$ \\
\hline PARTIDO DEL TRABAJO (PT) & SIN DATOS \\
\hline
\end{tabular}

Como es de apreciarse dos partidos no cuentan con datos, uno de ellos, el Partido Revolucionario Institucional como segunda fuerza electoral, no ofrece en su sitio ni en el Instituto Federal Electoral cifras del total de afiliadas (os).

De cara a las normas antes transcritas de orden que de origen dejan clara la intención 
Esta obra forma parte del acervo de la Biblioteca Jurídica Virtual del Instituto de Investigaciones Jurídicas de la UNAM

de los partidos políticos en eludir, una vez más, las normas que les obligan a las cuotas de género:

1. A través de la excepción a las candidaturas de mayoría relativa que sean resultado de un proceso democrático de elección, de acuerdo con los estatutos de cada partido;

2. Mediante la integración de fórmulas, de mayoría relativa o de representación proporcional, mujer y hombre indefectiblemente habrán de satisfacer lo prescrito en los artículos 218 y 220.1, respectivamente, pero que por el mismo esquema de dominación y sobreposición partidaria en las elecciones internas o primarias exista el acuerdo de la solicitud de licencia a favor de los suplentes (hombres).

Históricamente, cada tres años, las bancadas hacen movimientos para resarcir los lugares previstos para hombres, los que tuvieron que cedérselos de inicio a una mujer para cumplir con la cuota legal de género; esto es, el asunto conocido en México como "el caso Juanitas" resuelto por el Tribunal Electoral del Poder Judicial de la Federación a través del juicio para la protección de los derechos políticos electorales del ciudadano(a) en el expediente SUP-JDC-3049 y su acumulado SUP-JDC-3048/2009 y que desarrollaremos líneas siguientes.

Caso diverso es aquél de la observancia del principio de alternancia en la integración de las fórmulas de representación proporcional en segmentos de 5, expediente identificado como SUP-JDC 461/2009.

3. Si bien, las elecciones primarias pueden democratizar la selección de candidatos, este efecto puede ir en sentido contrario al efecto de las cuotas de género si, por ejemplo, los candidatos masculinos cuentan con más recursos de campaña, o con un mayor reconocimiento por parte del electorado. Es por ello que existe una tensión natural entre quienes buscan una mayor equidad de género en las candidaturas y quienes buscan una mayor democratización interna de los partidos;

4. El cumplimiento de las cuotas asignadas a mujeres que no gozan de arraigo o liderazgo en sus respectivas circunscripciones, de cara al género masculino que sí lo tienen. Estamos más que convencidas que los dirigentes partidarios diseñan su propia geografía electoral que les permite, antes que perder un escaño o curul, sacrificar a sus mujeres militantes.

5. En razón de su menor militancia y participación política, las mujeres no cuentan con el mismo capital político que los hombres de sus propios partidos, quienes escatiman 
Esta obra forma parte del acervo de la Biblioteca Jurídica Virtual del Instituto de Investigaciones Jurídicas de la UNAM

incluso los propios recursos asignados para campañas, salvo que, eventualmente, haya una mujer con mayores posibilidades.

Es evidente que las prácticas elusivas de los entes partidarios no tienen límites, en prospectiva a las elecciones 2012 y ante el déficit de credibilidad existe alta probabilidad que radicalicen sus estrategias desde las elecciones primarias de sus candidatos.

Finalmente, de una revisión de 2013 de los estatutos internos de los siete partidos políticos con registro nacional evidencian, en realidad nada distinto a lo supra indicado:

a) Prevén de manera muy general, la posibilidad de realizar elecciones primarias (sean abiertas a la ciudadanía o cerradas para afiliados y militantes);

b) Todos hablan de la necesidad de promover la participación de la mujer en los institutos políticos pero las Ilamadas "cuotas voluntarias" son muy heterogéneas, algunos incluyen paridad, otros cuota o recomendación; $y$,

c) En ninguno de los estatutos de los siete partidos se define lo que deberá entenderse por procedimiento democrático para la selección de sus candidatos. Sólo en caso de prever elecciones internas se limitan a mencionar el procedimiento; en otros casos, remiten a los reglamentos o convocatorias que se expiden exclusivamente para los procesos electorales próximos a realizarse.

\section{TUTELA JURISDICCIONAL EFECTIVA DE LOS DERECHOS POLÍTICOS DE LAS MUJERES: LA JURISDICCIÓN FEDERAL}

Veamos la labor pretoriana de los magistrados electorales federales.

\section{Sentencias relevantes}

En el 2002 el Tribunal Pleno de la Suprema Corte de Justicia de la Nación conoció la Acción de inconstitucionalidad 2/2002 promovida por el Partido Acción Nacional en contra del Decreto número 176 publicado en el Periódico Oficial del Estado de Coahuila el 16 de noviembre del año en curso mediante el cual se crea la Ley de Instituciones Políticas y Procedimientos Electorales para el Estado de Coahuila de Zaragoza, impugnándose en lo específico por esta acción de inconstitucionalidad los artículos 20, 21, 25, fracción I, 26, fracciones VII y VIII, 103, fracción IV, 107, 108, 109, 110, 111, 112 , $113,192,222,239$ y 240.

El partido argumentaba la inconstitucionalidad de una cuota de género tan elevada (70\%) toda vez que se disponía que los partidos políticos en representación proporcional 
Esta obra forma parte del acervo de la Biblioteca Jurídica Virtual del Instituto de Investigaciones Jurídicas de la UNAM

y mayoría relativa impulsarían la equidad de género, para el registro de candidatos tanto propietarios como suplentes.

La resolución resultó por demás polémica y dividida, los argumentos en contra tendían a determinar que la Ley de Instituciones Políticas y Procedimientos Electorales de Coahuila impone una cuota de género y que ésta carece de apoyo constitucional ya que el artículo 4o. establece la igualdad ante la ley de mujeres y hombres y que, por tanto, “...le está vedado al legislador plasmar cuotas de género, pues viola el derecho de igualdad político electoral de los ciudadanos de votar y ser votados...".

Sin embargo, la opinión a favor fue apoyada por la mayoría de los ministros, argumentando que la norma estudiada no está destinada a los ciudadanos sino a los partidos políticos, y que estas instituciones, al ser el mecanismo de acceso al poder de los ciudadanos, están sometidas a las formas específicas de intervención que la ley señale.

Sin lugar a dudas, fue una memorable resolución, ahora una lamentable regresión.

En el 2009, nuevamente el Pleno de la Corte conoció de acciones de inconstitucionalidad acumuladas en materia de cuotas de género consagradas en el Código Electoral de la entidad federativa de Veracruz Llave (7/2009, 8/2009 y 9/2009) promovidas por Convergencia, Partido Político Nacional, Partido Acción Nacional y Partido de la Revolución Democrática, de las cuales resolvió que el porcentaje de candidaturas que se destinan para las mujeres en los estados de la república, y que se lleva a cabo mediante las cuotas de género, puede ser menor a $40 \%$ del que se exige a nivel federal.

La decisión se tomó con el voto en contra de las dos ministras de la Corte.

En una votación dividida, la mayoría de ministros concluyó que la Constitución no garantiza ni fija cuotas de género y que los estados son libres de fijar el porcentaje.

Los estados tampoco están obligados a seguir el modelo del Código Federal de Instituciones y Procedimientos Electorales (Cofipe), en el que se obliga a los partidos a garantizar que el $40 \%$ de sus candidaturas a diputados y senadores serán de un mismo género, "procurando llegar a la paridad".

La Corte se pronunció sobre este tema al revisar algunos juicios de acciones de inconstitucionalidad que promovieron los partidos Acción Nacional y Convergencia en 
Esta obra forma parte del acervo de la Biblioteca Jurídica Virtual del Instituto de Investigaciones Jurídicas de la UNAM

contra de las recientes reformas electorales en Veracruz, donde, entre otros temas, sólo se reservó a las mujeres el 30\% de candidaturas locales a cargos de elección popular.

Como encargada de los juicios, la ministra Margarita Luna Ramos pidió a sus compañeros que se declarara inconstitucional este punto, porque llegó a la conclusión de que esta medida es discriminatoria e inequitativa.

Pero su propuesta no tuvo éxito. A ella sólo se sumaron el ministro Juan Silva Meza, y la ministra Olga Sánchez Cordero, quien expresó a sus compañeros que "una real equidad en materia de participación de géneros en la vida política de una sociedad y un Estado democrático, debe conseguirse procurando que tanto el hombre como la mujer cuenten con iguales oportunidades para acceder a cargos de elección popular".

La mayoría, integrada por seis ministros - debido a la ausencia de dos de los integrantes del Pleno-, no compartió sus argumentos y validó el sistema de cuotas de Veracruz, por considerarlo razonable. En especial porque antes de las reformas no existía el sistema de cuotas.

A manera de justificación, el entonces presidente de la Corte, Guillermo Ortiz Mayagoitia, dijo que el sentido de su voto habría sido el mismo si se hubiera fijado como fórmula de cuota de género un 50-50, 60-40 y hasta un 75-25.

El ministro Genaro Góngora argumentó que "la Constitución exige que el legislador repare las desigualdades pero deja en sus manos el diseño de mecanismos, sin que haya fundamento para imponer a estados, la solución adoptada a nivel central", cosas veredes que no creeredes.

Más allá de aquellas acciones de inconstitucionalidad o amparos en revisión que por imperativo del artículo 105, fracciones II y III de la Constitución federal llega a conocer en materia política el Tribunal Pleno de la Suprema Corte de Justicia de la Nación, los asuntos más paradigmáticos han sido conocidos por la Sala Superior del Tribunal Electoral de la Federación, multicitada en el presente documento, a través del medio de impugnación ad hoc como lo es el Juicio para la Protección de los Derechos Políticos Electorales del Ciudadano (JDC).

Sólo deseo dejar anotados dos casos que, desde mi óptica resultan modélicos en materia de protección de derechos, a saber:

1) SUP-JDC 461/2009 Alternancia de Género SX-JDC 159/2009, el caso específico 
Esta obra forma parte del acervo de la Biblioteca Jurídica Virtual del Instituto de Investigaciones Jurídicas de la UNAM

analizado es el juicio para la protección de los derechos político-electorales del ciudadano (JDC), interpuesto por Mary Telma Guajardo Villarreal, quien se inconforma por el lugar que le fue asignado en la lista de candidatos a diputados federales por el principio de representación proporcional (artículo 120.1, Cofipe) en la segunda circunscripción electoral plurinominal, integración avalada por el Segundo Pleno del Consejo Nacional del Partido de la Revolución Democrática (PRD), y luego ratificada por la Comisión Nacional de Garantías del mismo partido. Al no prosperar su pretensión en las instancias internas, Guajardo Villarreal interpuso un recurso ante el Tribunal Electoral del Poder Judicial de la Federación (TEPJF); en él argumentó que el lugar que le había sido asignado (el cuarto) no correspondía con los criterios de equidad de género establecidos por el Cofipe, en virtud de que tras una mujer -que estaba en primer lugar de la lista correspondiente-, se encontraban dos hombres y luego dos mujeres. La Sala Superior al resolver clarifica el concepto de alternancia en tanto uno a uno y en secuencia, restituye el derecho político de la quejosa a participar en elecciones internas partidarias y ser postulada, posteriormente, en el ámbito representativo democrático.

2) En este sentido es memorable el SUP-JDC-3049/2009 y su acumulado, el SUP-JDC3048/2009, el TEPJF admitió competencia para conocer de dos clases de peticiones. En una de ellas, una diputada federal en funciones, Olga Luz Espinosa Morales, quien solicitó licencia definitiva, pidió al Tribunal obligar a la Cámara de Diputados a resolver en forma definitiva una solicitud de licencia al cargo de representación del que es titular; a su vez, en la segunda petición, un diputado federal suplente precisamente en la fórmula de la legisladora Espinosa Morales, y quien, no estaba en funciones, solicitó al Tribunal que revocar y ordenar a la Mesa Directiva de la Cámara de Diputados o a la Comisión Permanente del Congreso de la Unión que le llamen para tomar protesta para asumir el cargo de diputado federal.

\section{Vuelta a la tuerca: una sentencia paliativo} ¿con repercusiones a futuro?

El 30 de noviembre de 2011 la Sala Superior del Tribunal Electoral del Poder Judicial de la Federación emitió una resolución en el Juicio para la Protección de los Derechos Políticos Electorales, SUP-JDC-12624/2011 y acumulados, incoados por María Elena Chapa Hernández, María de las Nieves García Fernández, María Cruz García Sánchez, Refugio Esther Morales Pérez, Rocío Lourdes Reyes Willie, María Fernanda Rodríguez Calva, María 
Esta obra forma parte del acervo de la Biblioteca Jurídica Virtual del Instituto de Investigaciones Jurídicas de la UNAM www.juridicas.unam. $\mathrm{mx}$

Juana Soto Santana, Martha Angélica Tagle Martínez, María de los Ángeles Moreno Uriegas y Laura Cerna Lara, ${ }^{20}$ con la finalidad de impugnar el acuerdo CG327/2011, "Acuerdo del Consejo General del Instituto Federal Electoral por el que se indican los criterios aplicables para el registro de candidaturas a los distintos cargos de elección popular que presenten los partidos políticos y, en su caso, las coaliciones ante los Consejos del Instituto, para el proceso electoral federal 2011-2012".

La resolución se considera un hito en el cumplimiento de cuotas de género que, indefectiblemente lleva a la equidad entre los géneros. ${ }^{21}$

En estricto sentido, los puntos nodales combatidos por las accionantes en tutela de la protección de sus derechos políticos-electorales se enderezan en contra del décimo tercer punto del acuerdo de referencia, específicamente en sus párrafos cuarto (íntegro) y la expresión "procurando", así como los párrafos tercero y quinto por lo que hace a los criterios aplicables para el registro de candidaturas a los distintos cargos de elección popular que presenten los partidos políticos y, en su caso, las coaliciones.

\footnotetext{
${ }^{20}$ En estricto sentido el proveído del magistrado instructor se enderezó a decretar la acumulación de los expedientes identificados con las claves SUP-JDC-12624/2011, SUP-JDC-12625/2011, SUPJDC- 2626/2011, SUP-JDC-12627/2011, SUP-JDC-12628/2011，SUP-JDC-12629/2011，SUP-JDC-12630/2011，SUP-JDC-12631/2011，SUP-JDC-12634/2011 y SUP-JDC-12635/2011.

21 Más allá de los diversos conceptos en torno a la equidad de género, afirmamos que el término sustantivo que soporta su contenido es el de proporcionalidad en tanto que en sí mismo predica la defensa de la igualdad entre hombres y mujeres en todo lo que implica el goce y ejercicio de derechos, en situaciones sustantivas como aquellas que se dirigen al acceso y uso de los bienes y servicios en el contexto del estado constitucional y democrático. Así, el concepto de proporcionalidad, como un tertium comparationis. Esto supone abolir la discriminación entre ambos sexos y que no se privilegie al hombre en ningún aspecto de la vida social, tal como era frecuente hace algunas décadas en la mayoría de las sociedades occidentales.
}

La equidad de género consiste en estandarizar las oportunidades existentes para repartirlas de manera justa entre ambos sexos. Los hombres y las mujeres deben contar con las mismas oportunidades para el desarrollo. El Estado, por lo tanto, tiene que garantizar que los recursos sean asignados de manera simétrica.

Una mujer no debe obtener menos salario que un hombre ante un mismo trabajo. Cualquier persona debe ganar lo que le sea propio de acuerdo a sus méritos y no puede ser favorecida en perjuicio del prójimo. Un hombre y una mujer deben recibir la misma remuneración ante un mismo trabajo que contemple idénticas obligaciones y responsabilidades.

Esta situación de equidad debe alcanzarse sin descuidar las características de género. Las mujeres, por ejemplo, tienen derecho a una extensa licencia por maternidad, mientras que la licencia por paternidad es más breve. En este caso, se atiende a las cuestiones biológicas y se realiza una discriminación positiva entre ambos sexos. 
Esta obra forma parte del acervo de la Biblioteca Jurídica Virtual del Instituto de Investigaciones Jurídicas de la UNAM

Expresado en términos de agravios, podríamos indicar que se ciñen las impugnaciones a los elementos siguientes:

1) El exceso de reglamentación por parte del Consejo General en relación con el artículo 219 del Código Federal de Instituciones y Procedimientos Electorales, por lo que hace a la definición de la expresión "procesos democráticos".

2) La frase "procurando que la fórmula completa se integre por candidatos del mismo género" contenida en los párrafos tercero y quinto del punto de acuerdo decimotercero del acuerdo CG327/2011.

Por lo que hace al primer punto, y contraviniendo en el principio de legalidad contenido en los artículos 14 y 16, y el diverso de certeza jurídica del artículo 41, todos de la Constitución federal, el Consejo General al definir el concepto de "proceso democrático" y remitir, eventualmente, a los estatutos de los partidos políticos para exceptuar de la cuota de género a las candidaturas de mayoría relativa, se excedió de la facultad reglamentaria que los artículos 3o. y 118 del Cofipe le reconocen, máxime cuando de forma tan osada exceptúa, también a las “candidaturas que se realizaran de forma indirecta a través de una convención o asamblea en la que participe un número importante de delegados electos ex profeso por dicha militancia."

Para los consejeros ¿qué es un número importante de delegados electos ex profeso"?

Por lo que hace al punto dos, la Sala Superior, tal como lo expresaron las impugnantes, asumieron en toda su dimensión la ratio contenida en el párrafo segundo del artículo 219 que en forma alguna contiene una recomendación a los partidos políticos para observar la cuota; el imperativo normativo lo es tanto como obligación, tal cual es la intención de paliar el estado de desventaja e inclusividad de uno de los géneros, al caso el femenino, en la representación política.

Aunado a lo anterior, la meridianidad con la que la sentencia trata la cuota de género respecto de su conformación en la posición de propietaria y suplente, está enderezada al $40 \%$ reservada, en la transitoriedad, a las mujeres. Esto es así como un mecanismo para garantizar que no se dará la elusión electoral concretada en las elecciones de 2009, con las ya referidas líneas de las “Juanitas".

Un punto a favor de la sentencia lo es la invocación a los instrumentos internacionales de los derechos humanos en materia de igualdad de género y titularidad, y ejercicio de los derechos políticos-electorales. 
Esta obra forma parte del acervo de la Biblioteca Jurídica Virtual del Instituto de Investigaciones Jurídicas de la UNAM www.juridicas.unam.mx

Finalmente vale mencionar los puntos resolutivos de la sentencia:

1. Se ordena al Consejo General expulsar el párrafo cuarto del Punto Décimo Tercero del Acuerdo;

2. Del mismo Punto modifica como se transcribe los párrafos tercero y quinto:

Esto es, en caso de que el partido político, elija a sus candidatos de mayoría relativa mediante un proceso de elección democrático observando y privilegiando lo previsto en sus estatutos respecto de la forma de elección, el partido político o coalición, en todo caso, deberá presentar como mínimo 120 y 26 candidatos propietarios de un mismo género, a Diputados y Senadores, respectivamente en términos de lo dispuesto por el primer párrafo del artículo 219 del Código Federal de Instituciones y Procedimientos Electorales.

Las listas de representación proporcional se integrarán por segmentos de cinco candidaturas. En cada uno de los segmentos de cada lista habrá dos candidaturas de género distinto, de manera alternada. En el caso de las candidaturas que conforman la cuota de género prevista en el artículo 220, párrafo primero, del Código Federal de Instituciones y Procedimientos Electorales (mínimo cuarenta por ciento del total), la fórmula completa (propietario y suplente) debe integrarse por candidatos del mismo género. Tratándose de la lista de candidatos a Senadores, los dos últimos lugares serán ocupados por un candidato de cada género.

\section{Bordando fino}

El 14 de diciembre de 2011 el Consejo General del Instituto Federal en cumplimiento a la sentencia expuesta, emite el Acuerdo CG413/2011 y modificatorio del diverso CG327/2011, sólo en lo que hace a los párrafos tercero, cuarto y quinto, quedando como sigue:

DÉCIMO TERCERO. De la totalidad de solicitudes de registro de candidaturas a Diputados y Senadores, tanto de mayoría relativa como de representación proporcional, que presenten los partidos políticos o coaliciones ante el Instituto Federal Electoral, en ningún caso incluirán más del sesenta por ciento de candidatos propietarios de un mismo género. Además, se verificará que los partidos políticos hayan observado los porcentajes de género establecidos en sus propios Estatutos.

Quedan exceptuadas de la regla de género señalada en el párrafo anterior, las candidaturas de mayoría relativa que sean resultado de un proceso de elección democrático.

Esto es, en caso de que el partido político elija a sus candidatos de mayoría relativa mediante un proceso de elección democrático, observando y privilegiando lo previsto en 
Esta obra forma parte del acervo de la Biblioteca Jurídica Virtual del Instituto de Investigaciones Jurídicas de la UNAM www.juridicas.unam.mx

CG413/2011 sus Estatutos respecto de la forma de elección, el partido político o coalición, en todo caso, deberá presentar como mínimo 120 y 26 candidatos propietarios de un mismo género, a Diputados y Senadores, respectivamente en términos de lo dispuesto por el primer párrafo del artículo 219 del Código Federal de Instituciones y Procedimientos Electorales.

Las listas de representación proporcional se integrarán por segmentos de cinco candidaturas. En cada uno de los segmentos de cada lista habrá dos candidaturas de género distinto, de manera alternada. En el caso de las candidaturas que conforman la cuota de género prevista en el artículo 220, párrafo primero, del Código Federal de Instituciones y Procedimientos Electorales (mínimo cuarenta por ciento del total), la fórmula completa (propietario y suplente) debe integrarse por candidatos del mismo género. Tratándose de la lista de candidatos a Senadores, los dos últimos lugares serán ocupados por un candidato de cada género.

La secuela procesal no queda sólo en la emisión del Acuerdo antes indicado sino que, además, en noviembre de 2011, el secretario general del Consejo ante la Sala Superior del Tribunal Electoral del Poder Judicial de la Federación presenta un escrito de aclaración de sentencia en relación con los efectos de la sentencia del SUP-JDC$12624 / 2011$ y acumulados; ${ }^{22}$ por lo que podemos decir, un tanto “premonitorio" respecto del eventual no cumplimiento de las cuotas conforme a los procedimientos establecidos en los estatutos de cada uno de los partidos políticos, particularmente en los mecanismos de selección vía procesos democráticos de cara a la insuficiente participación y triunfo de las mujeres para satisfacer la cuota hic et nunc, ${ }^{23}$ obligada de género.

Más aún, la aclaración se encamina a plantear tanto el supuesto de hacer nugatorios los derechos del sufragio pasivo de los varones militantes de los institutos políticos, en aras del cumplimiento de las cuotas, así como lo atinente a las candidaturas que ya habían sido materia de asignación $y$, en consecuencia, la eventual vulneración de derechos adquiridos.

\footnotetext{
${ }^{22}$ Véase IFE, ruta crítica de la cuota de género a nivel federal. Evolución jurisdiccional, México, marzo de 2012.

${ }^{23}$ Decimos que el efecto de la sentencia es hic et nunc, en razón que es a partir del planteamiento de su disconformidad que rige desde el momento en que es emitida y causa estado sólo para los casos a futuro, no puede, bajo ningún concepto tener efectos ex tunc, en virtud que en ningún resolutivo se retrotraen los efectos de la referida sentencia a casos anteriores y no podría toda vez que tal como lo hizo el secretario general del Consejo General del IFE, se vulneran derechos adquiridos.
} 
Esta obra forma parte del acervo de la Biblioteca Jurídica Virtual del Instituto de Investigaciones Jurídicas de la UNAM

El resultado del incidente era previsible, id est, se declaró improcedente ciñendo, los efectos de la sentencia a los puntos ya transcritos (definiens definium).

Hasta el momento en que se escribe el presente documento se han interpuesto cuatro juicios para la protección de los derechos políticos electoral del ciudadano, SUPJDC-14855/2011 y acumulados (23 de diciembre de 2011), en contra del CG413/2011 mediante el cual el Consejo General del IFE cumplimenta la resolución recaída al multireferido SUP-JDC 12624/2011, desde luego, argumentando violación al derecho a ser votados en los procesos de selección interna en mayoría relativa o postulados en los segmentos de representación proporcional, afectación al principio de autonomía de auto-organización partidaria, y a los derechos adquiridos, inter alia. El medio de impugnación fue desechado y confirma el acuerdo sustitutorio.

No es el quid del presente documento narrar el iter de eventos que se han sucedido, los cuales van desde los escritos presentados por los partidos políticos ante el Consejo General del IFE, fundamentando el eventual incumplimiento de las cuotas de género por ambos principios electorales en virtud de la insuficiencia de mujeres en las contiendas internas en mayoría relativa o a efecto de su inserción en las listas de representación proporcional.

En este sentido, quizá resulta más ilustrativo el informe presentado por el presidente del Consejo General del Instituto Federal Electoral ante el órgano máximo del ente administrativo electoral federal el 26 de marzo de 2012 y que causó revuelo ante el incumplimiento de los partidos políticos respecto a la cuota de género y sus eventuales sanciones. ${ }^{24}$

El 28 de marzo, a un día de inicio formal de las campañas electorales, los institutos políticos, cumplieron "voluntariamente" con la cuota obligatoria, así el PAN anunció que sustituyó a 44 hombres; el PRI y PVEM a 54, y el PRD, PT y Movimiento Ciudadano a 28.

Pero es una triste realidad: las cuotas vuelven a ser utilizadas para beneficio de los mismos; la sustitución que se verificó es elusiva de la cuota, ya que quienes aún integran fórmula guardan cualquier vínculo de parentesco con quienes ya no son, a guisa de ejemplo: La hermana de la hasta ahora gobernadora de Yucatán, Guadalupe Ortega

\footnotetext{
${ }^{24}$ Informe que presenta el consejero presidente del Consejo General del Instituto Federal Electoral, respecto a la cuota de género prevista en los artículos 219 y 220 del Código Federal de Instituciones y Procedimientos Electorales con relación al numeral 221 del mismo ordenamiento legal y al acuerdo del Consejo General CG413/2011, del 26 de marzo de 2012.
} 
Esta obra forma parte del acervo de la Biblioteca Jurídica Virtual del Instituto de Investigaciones Jurídicas de la UNAM www.juridicas.unam.mx

Pacheco, subió a candidata a diputada federal en la 3ra circunscripción y María del Carmen Ordaz, esposa de José Blanco, ex alcalde de Progreso Blanco Pajón, bajó y su cónyuge ahora es la candidata a la diputación del 2 do distrito electoral federal. El procedimiento en todos los casos y entidades es el mismo. Do ut des y dicho en buen castellano palaciego "doy para que des", la mano visible del "jardín secreto de las candidaturas", ${ }^{25}$ las Juanitas en el proceso 2012 han parido una nueva modalidad.

\section{Los resultados de la elección federal}

\section{2 en las colegisladoras}

Las elecciones celebradas el 10. de julio de 2012, en las que contendieron siete partidos políticos nacionales arrojaron los siguientes resultados por la Cámara legislativa federal:

Cámara de Diputados ${ }^{26}$

\begin{tabular}{|l|l|l|l|}
\hline Partido & Sexo & $M r$ & $R p$ \\
\hline \multirow{4}{*}{ PAN } & Mujeres & 8 & 28 \\
\cline { 2 - 4 } & Hombres & 44 & 34 \\
\cline { 2 - 4 } & Mujeres & 58 & 23 \\
\cline { 2 - 4 } & Hombres & 106 & 26 \\
\cline { 2 - 4 } & Mujeres & 17 & 21 \\
\cline { 2 - 4 } & Hombres & 42 & 23 \\
\cline { 2 - 4 } & Mujeres & 1 & 5 \\
\cline { 2 - 4 } & Hombres & 3 & 6 \\
\cline { 2 - 4 } & Mujeres & 5 & 7 \\
\cline { 2 - 4 } & Hombres & 8 & 8 \\
\cline { 2 - 4 } & Mujem & 2 & 5 \\
\cline { 2 - 4 } & & & \\
\cline { 2 - 4 } & MOVIMIENTO & &
\end{tabular}

\footnotetext{
${ }^{25}$ Dahlerup, Drude y Freidenvall, Lenita, Sistemas electorales de cuotas de género y su aplicación en Europa. Derechos de las mujeres e igualdad de género, Bruselas, Parlamento Europeo, 2008, pp. 2 y 17.
}

26 Fuente: INE, http://siceef.ife.org.mx/pef2012/SICEEF2012.html\#app=ff36\&88fe-selectedIndex=3\&bd55selectedIndex $=0 \&$ ea $8 f$-selectedIndex $=0 \& 6 b 4 e-$ selectedIndex $=0 \& f c 11$-selectedInde $x=0$ 
Esta obra forma parte del acervo de la Biblioteca Jurídica Virtual del Instituto de Investigaciones Jurídicas de la UNAM www.juridicas.unam.mx https://biblio.juridicas.unam.mx/bjv https://revistas.juridicas.unam.mx/

DOI: http://dx.doi.org/10.22201/iij.24487910e.2015.7.10087

\begin{tabular}{|l|l|l|l|}
\cline { 2 - 4 } & Hombres & 6 & 4 \\
\cline { 2 - 4 } ALIANZA & Mujeres & 0 & 5 \\
\hline
\end{tabular}

En relación con los resultados electorales, el número de mujeres se ha incrementado en la Cámara de Diputados, de 2006 a 2012 en 77 mujeres más; por lo que hace a la elección 2009 en 46 mujeres. Para mejor apreciación, el número de diputadas en 2006 fue por ambos principios de 108; en 2009 se obtuvieron 139 y, en la elección 2012 se lograron 185.

\begin{tabular}{|c|c|c|c|}
\hline Partido & Sexo & $M r$ & $R p$ \\
\hline \multirow[t]{2}{*}{ PAN } & Mujeres & 7 & 4 \\
\hline & Hombres & 22 & 5 \\
\hline \multirow[t]{2}{*}{ PRI } & Mujeres & 14 & 5 \\
\hline & Hombres & 29 & 6 \\
\hline \multirow[t]{2}{*}{ PRD } & Mujeres & 3 & 3 \\
\hline & Hombres & 13 & 3 \\
\hline \multirow[t]{2}{*}{ PVEM } & Mujeres & 1 & 1 \\
\hline & Hombres & 4 & 1 \\
\hline \multirow[t]{2}{*}{ PT } & Mujeres & 1 & 1 \\
\hline & Hombres & 2 & 1 \\
\hline \multirow{2}{*}{$\begin{array}{l}\text { MOVIMIENTO } \\
\text { CIUDADANO }\end{array}$} & Mujeres & 0 & 1 \\
\hline & Hombres & 0 & 0 \\
\hline ALIANZA & Mujeres & 0 & 1 \\
\hline
\end{tabular}

Por lo que hace a la Cámara de Senadores de la elección de 2006 en la que se obtuvieron 23 curules para mujeres por ambos principios de cara a los resultados 2012

27 INE, http://siceef.ife.org.mx/pef2012/SICEEF2012.html\#app=ff36\&88fe-selectedIndex $=3 \& b d 55$ selectedIndex $=2 \&$ ea $8 f$-selectedInde $=0 \& 6 b 4 e$-selectedIndex $=0 \& f$ c 11 -selectedIndex $=0$ 
Esta obra forma parte del acervo de la Biblioteca Jurídica Virtual del Instituto de Investigaciones Jurídicas de la UNAM www.juridicas.unam.mx

en que las mujeres ganaron 42, el logro en términos de incremento de representación de género femenino es de 19.

\section{LA REFORMA 2014 Y LA RUTA INCLUSIVA DE LAS MUJERES}

\section{El cambio normativo constitucional y las leyes} de desarrollo del principio paritario

Las anunciadas reformas político-electorales en el sexenio del presidente Peña Nieto Pacto por México-, finalmente se cristalizaron con su publicación en el Diario Oficial de la Federación del 10 febrero de 2014, evidenciando un cambio cuántico en el esquema de la inclusión de las mujeres en el ámbito político electoral. ${ }^{28}$

La inclusión del principio de igualdad o principio paritario en materia de representación política se proyecta como una extensión del enunciado contenido en el acápite del artículo 4o. de la Constitución federal que predica la igualdad formal entre "varones y mujeres", previsión que no estuvo en el texto original publicado en el Diario Oficial de la Federación del 5 de febrero de 1917, su reconocimiento arriba con la reforma publicada el 31 de diciembre de 1974.

El artículo 41, párrafo segundo, fracción I, segundo párrafo, prescribe que:

...Los partidos políticos tienen como fin promover la participación del pueblo en la vida democrática, contribuir a la integración de los órganos de representación política y como organizaciones de ciudadanos, hacer posible el acceso de éstos al ejercicio del poder

\footnotetext{
${ }^{28}$ Peña Molina, Blanca Olivia, La paridad de género en candidaturas a cargo de elección popular: avances y retos en los congresos estatales ayuntamientos en México, https://www.somee.org.mx/download.php? $t=2 \& c=3 \& h=d 531 e c 4 e d 3318 e a 33 f f b 1160926 e 28748 b c b b 8 f e$. En el marco del evento conmemorativo del LX aniversario del sufragio femenino en México efectuado el 11 de octubre del 2013, la Presidencia de la República envió al Senado una iniciativa para reformar el Código Federal de Instituciones y Procedimientos Electorales (Cofipe), el objetivo: garantizar el ejercicio de los derechos políticos de las mujeres a cargos de elección popular en el ámbito federal. La iniciativa contemplaba la adición y derogación de algunos artículos para incluir el principio de paridad de género en candidaturas a cargos de elección popular para integrar el Congreso de la Unión.

La propuesta del Ejecutivo contemplaba la reforma de los artículos 218, 219 y 220, así como la derogación del numeral 2 del artículo 219 del Cofipe, párrafo donde se exentaba a los partidos el cumplimiento de la cuota de género (40\%) cuando la selección de candidaturas por el principio de mayoría relativa (MR) fuera resultado de un proceso democrático de acuerdo a los estatutos de los partidos políticos. Los cambios de redacción propuestos se resumen en el siguiente cuadro.
} 
Esta obra forma parte del acervo de la Biblioteca Jurídica Virtual del Instituto de Investigaciones Jurídicas de la UNAM www.juridicas.unam. $\mathrm{mx}$

DOI: http://dx.doi.org/10.22201/iij.24487910e_2015.7.10087

público, de acuerdo con los programas, principios e ideas que postulan y mediante el sufragio universal, libre, secreto y directo, así como las reglas para garantizar la paridad entre los géneros, en candidaturas a legisladores federales y locales.

Entendiéndose la obligación a cargo, en principio, de los partidos políticos y —por lo que hace a las leyes de desarrollo previstas en el artículo 73, fracciones XXI, inciso a) y la diversa XXIX-U—, al legislador ordinario conforme a la fracción II del artículo segundo transitorio del decreto de reformas y adiciones constitucionales de 2014, que a la letra dispone que la Ley General de Procedimientos Electorales deberá contener, inciso h) “...Las reglas para garantizar la paridad entre géneros en candidaturas a legisladores federales y locales ...".

Ambas leyes generales, tanto de Instituciones y Procedimientos Electorales (en adelante LGIPE) como la de Partidos Políticos (por sus siglas LGPP) —ambas, regulatorias del principio igualitario en materia política- se publicaron en el Diario Oficial de la Federación del 23 de mayo de 2014.

La LGIPE contiene las reglas del principio de paridad en candidaturas: ${ }^{29}$

\footnotetext{
${ }^{29}$ Peña Molina, Blanca Olivia, "Paridad de género en México: anverso y reverso", condistintosasentos. Investigación y reflexión sobre América Latina, http://www.condistintosacentos.com/paridad-de-genero-en-mexico-anverso-y-reverso/
} 
Esta obra forma parte del acervo de la Biblioteca Jurídica Virtual del Instituto de Investigaciones Jurídicas de la UNAM www.juridicas.unam.mx

\begin{tabular}{|l|l|}
\hline $\begin{array}{l}\text { Derecho al } \\
\text { sufragio }\end{array}$ & $\begin{array}{l}\text { Votar en las elecciones constituye un derecho de hombres y } \\
\text { mujeres y una obligación para los partidos de garantizar la } \\
\text { igualdad de oportunidades y la paridad para tener acceso a cargos } \\
\text { de elección popular (Artículo 7). }\end{array}$ \\
\hline $\begin{array}{l}\text { Tipo de } \\
\text { candidaturas }\end{array}$ & $\begin{array}{l}\text { Aplicación del principio de paridad para candidaturas a cargos de elección } \\
\text { popular para integrar ambas Cámaras, los Congresos locales y la ADF; } \\
\text { obligación aplicable a los partidos, coaliciones y también a la nueva figura de } \\
\text { candidaturas independientes (Artículos 14, 233 y 234). }\end{array}$ \\
\hline $\begin{array}{l}\text { Suplencia de } \\
\text { género }\end{array}$ & $\begin{array}{l}\text { Las fórmulas de integración candidaturas para las Cámaras de Diputados y } \\
\text { Senadores deberán conformarse con personas del mismo género, tanto por el } \\
\text { principio de mayoría relativa como de representación proporcional (Artículos } \\
\text { 14 y 234). }\end{array}$ \\
\hline $\begin{array}{l}\text { Alternancia } \\
\text { de género }\end{array}$ & $\begin{array}{l}\text { Se mandata que en la integración de listas de representación proporcional, } \\
\text { además de la suplencia del mismo género, éstas se integren en forma } \\
\text { alternada hasta agotar cada lista como garantía al principio de paridad. Este } \\
\text { criterio aplica también en las fórmulas de candidatos para el Senado (Artículo } \\
\text { 234). }\end{array}$ \\
\hline $\begin{array}{l}\text { Usos } \\
\text { costumbres }\end{array}$ & $\begin{array}{l}\text { Deberán garantizarse la participación de hombres y mujeres en condiciones } \\
\text { de igualdad, guardando las normas establecidas en la CPEUM, las } \\
\text { constituciones locales y leyes aplicables (Artículo 26). }\end{array}$ \\
\hline Sanciones & $\begin{array}{l}\text { Se enfatiza la facultad del Instituto Nacional Electoral (INE) y de los } \\
\text { Organismos Públicos Locales (OPL) para rechazar el registro del número de } \\
\text { candidaturas de un género que exceda la paridad, esto es, más del 50 por } \\
\text { ciento, exigiendo sustitución improrrogable en un plazo establecido y de no } \\
\text { ser sustituidas sancionarán con la negativa de registro (Artículos 232 y 241). }\end{array}$ \\
\hline
\end{tabular}

Por su parte la LGPP regula la paridad política: ${ }^{30}$

${ }^{30}$ Idem. 
Esta obra forma parte del acervo de la Biblioteca Jurídica Virtual del Instituto de Investigaciones Jurídicas de la UNAM www.juridicas.unam.mx

\begin{tabular}{|c|c|}
\hline Obligaciones & $\begin{array}{l}\text { Promover valores cívicos y cultura democrática en niños, niñas y } \\
\text { adolescentes, así como la participación efectiva de hombres y mujeres en } \\
\text { integración de órganos internos y candidaturas. Determinar criterios y } \\
\text { hacerlos públicos para garantizar paridad de género en ambas Cámaras, } \\
\text { Congresos locales y ALDF. Inadmisión de criterios que discriminen } \\
\text { asignación de candidaturas en distritos perdedores para un solo género. } \\
\text { Garantizar la paridad de género en candidaturas (Artículos } 3,25,37 \text { ). }\end{array}$ \\
\hline $\begin{array}{l}\text { Derechos } \\
\text { militancia }\end{array}$ & $\begin{array}{l}\text { La Ley señala que los partidos políticos deberán establecer los derechos de } \\
\text { su militancia, entre los que se incluirán, al menos, tres casos: a) } \\
\text { participación personal y directa o por medio de delegados en las } \\
\text { asambleas, consejos, convenciones o equivalentes para la toma de } \\
\text { decisiones internas; b) postulación como candidato a cargos de elección } \\
\text { popular dentro de los procesos internos de selección (internas primarias), } \\
\text { para lo cual deberán cumplir con los requisitos que se establezcan en } \\
\text { disposiciones aplicables y en los estatutos de cada partido; c) postulación } \\
\text { como dirigente del partido o cualesquier otro empleo o comisión al } \\
\text { interior de acuerdo a los requisitos establecidos en los estatutos (Artículo } \\
\text { 40). }\end{array}$ \\
\hline $\begin{array}{l}\text { Financiamiento } \\
\text { capacitación } \\
\text { mujeres }\end{array}$ & $\begin{array}{l}\text { Incremento del } 2 \text { al } 3 \text { por ciento de financiamiento ordinario del partido } \\
\text { para la capacitación, promoción y desarrollo del liderazgo político de las } \\
\text { mujeres. Asimismo se precisan los rubros en los que deberán aplicarse los } \\
\text { recursos destinados a estas actividades (Artículos } 51 \text { y } 73 \text { ). }\end{array}$ \\
\hline $\begin{array}{l}\text { Gastos de } \\
\text { campaña }\end{array}$ & $\begin{array}{l}\text { Como requisito a cumplir la Ley consigna que los gastos que realice el } \\
\text { partido, las coaliciones y los candidatos deberán sujetarse a criterios de } \\
\text { legalidad, honestidad, eficiencia, eficacia, economía, racionalidad, } \\
\text { austeridad, transparencia, control, rendición de cuentas y equidad de } \\
\text { género (Artículo 63). }\end{array}$ \\
\hline
\end{tabular}

\section{Una breve digresión: la integración de los Organismos}

\section{Públicos Locales Electorales}

Consecuencia de las reformas constitucionales en materia política electoral, se determina la restructuración orgánica, funcional, competencial y nominal del órgano administrativo electoral federal el cual de ser un instituto federal se convierte en uno de ámbito nacional, con todo lo que de suyo implica.

La designación de los nuevos consejeros nacionales electorales, ahora 11, incluido el presidente, fue publicada en el Diario Oficial de la Federación del 4 de abril de 2014.

En junio el Consejo General del INE, a la vera de la expedición de las leyes de desarrollo en materia de instituciones y procedimientos electorales y la de partidos políticos supra indicadas, aprobó la convocatoria para proceder a la selección de los integrantes de los organismos públicos locales electorales (Ople's) que habría de estar a cargo del CENEVAL, en el diseño y aplicación de un examen por reactivos, y en el cual participamos varios académicos en la denominada validación; en agosto el mismo INE 
Esta obra forma parte del acervo de la Biblioteca Jurídica Virtual del Instituto de Investigaciones Jurídicas de la UNAM www.juridicas.unam.mx

aprobó los lineamientos para la segunda fase de depuración de los aspirantes, consistente en un ensayo presencial a 25 hombres y 25 mujeres por cada entidad federativa, resultando seleccionados los de mayor puntuación, se suma al procedimiento la depuración curricular a cargo del INE y los partidos políticos.

Lo interesante es la integración de los Ople's por entidad federativa (18) y por género, veamos: ${ }^{31}$

Consejeros(as) OPLE'S

\begin{tabular}{|l|l|l|}
\hline Entidad federativa & Hombres & Mujeres \\
\hline Baja California Sur & 2 & 5 \\
\hline Campeche & 2 & 5 \\
\hline Colima & 2 & 5 \\
\hline Chiapas & 2 & 5 \\
\hline Distrito Federal & 4 & 3 \\
\hline Guanajuato & 4 & 3 \\
\hline Guerrero & 3 & 4 \\
\hline Jalisco & 4 & 3 \\
\hline Estado de México & 4 & 3 \\
\hline Michoacán & 4 & 3 \\
\hline Morelos & 3 & 4 \\
\hline Nuevo León & 3 & 4 \\
\hline Oaxaca & 4 & 3 \\
\hline Querétaro & 3 & 4 \\
\hline San Luis Potosí & 2 & 5 \\
\hline Sonora & 3 & 4 \\
\hline
\end{tabular}

\footnotetext{
${ }^{31}$ Los nombres de los integrantes de los Ople’s, cargo y duración son visibles en INE/CG165/2014, Acuerdo del Consejo General del Instituto Nacional Electoral por el cual se aprueba la designación de consejeras (os) presidentes, y consejeras (os) electorales de organismos públicos locales electorales.
} 
Esta obra forma parte del acervo de la Biblioteca Jurídica Virtual del Instituto de Investigaciones Jurídicas de la UNAM www.juridicas.unam.mx https://biblio.juridicas.unam.mx/bjv https://revistas.juridicas.unam.mx/

DOI: http://dx.doi.org/10.22201/iij_.24487910e_2015.7.10087

\begin{tabular}{|l|l|l|}
\hline Tabasco & 4 & 3 \\
\hline Yucatán & 4 & 3 \\
\hline
\end{tabular}

Por lo que hace a la designación de los magistrados(as) de los tribunales electorales de 17 entidades federativas, los resultados fueron los siguientes:

Magistrados(as) tribunales electorales estatales

\begin{tabular}{|c|c|c|}
\hline Entidad federativa & $\begin{array}{l}\text { Hombre } \\
\text { s }\end{array}$ & $\begin{array}{r}\quad \text { Mujere } \\
s\end{array}$ \\
\hline Baja California Sur & 3 & 0 \\
\hline Campeche & 1 & 2 \\
\hline Colima & 3 & 2 \\
\hline Chiapas & 4 & 1 \\
\hline Distrito Federal & 3 & 2 \\
\hline Guanajuato & 3 & 0 \\
\hline Guerrero & 4 & 1 \\
\hline Jalisco & 4 & 1 \\
\hline Estado de México & 5 & 0 \\
\hline Michoacán & 5 & 0 \\
\hline Morelos & 3 & 0 \\
\hline Nuevo León & 3 & 0 \\
\hline Oaxaca & --- & --- \\
\hline Querétaro & 3 & 2 \\
\hline San Luis Potosí & 2 & 1 \\
\hline Sonora & 2 & 1 \\
\hline Tabasco & 2 & 1 \\
\hline Yucatán & 2 & 1 \\
\hline
\end{tabular}

\section{3}

DR @ 2018. Instituto de Investigaciones Jurídicas, UNAM, 
Esta obra forma parte del acervo de la Biblioteca Jurídica Virtual del Instituto de Investigaciones Jurídicas de la UNAM www.juridicas.unam. $\mathrm{mx}$

DOl: http://dx_doi.org/10.22201/iij].24487910e.2015.7.10087

\section{La paridad en las entidades federativas: el estado} de la cuestión en números

En un recuento de las entidades federativas que se encuentran en plena observancia del principio paritario tenemos:

\begin{tabular}{|c|c|c|c|c|}
\hline $\begin{array}{l}\text { Principio paritario } \\
\text { electoral congresos }\end{array}$ & $\begin{array}{l}\text {-iguali } \\
\text { estata }\end{array}$ & io en & nateric & política \\
\hline & Cons & Ición & $\begin{array}{l}\text { Legis } \\
\text { elect }\end{array}$ & $\begin{array}{l}\text { ción } \\
\text { al }\end{array}$ \\
\hline Entidad federativa & Cong & & & \\
\hline & MR & $\mathrm{RP}$ & MR & $\mathrm{RP}$ \\
\hline $\begin{array}{l}1 \text { Baja California } \\
\text { Sur }\end{array}$ & $50 \%$ & $50 \%$ & $50 \%$ & $50 \%$ \\
\hline 2 Campeche & $50 \%$ & $50 \%$ & $50 \%$ & $50 \%$ \\
\hline 3 Chiapas & $50 \%$ & $50 \%$ & $50 \%$ & $50 \%$ \\
\hline 4 Colima & $50 \%$ & $50 \%$ & $50 \%$ & $50 \%$ \\
\hline 5 Distrito Federal & $50 \%$ & $50 \%$ & $50 \%$ & $50 \%$ \\
\hline 6 Estado de México & $50 \%$ & $50 \%$ & $50 \%$ & $50 \%$ \\
\hline 7 Guanajuato & $50 \%$ & $50 \%$ & $50 \%$ & $50 \%$ \\
\hline 8 Guerrero & $50 \%$ & $50 \%$ & $50 \%$ & $50 \%$ \\
\hline 9 Jalisco & $50 \%$ & $50 \%$ & $50 \%$ & $50 \%$ \\
\hline 10 Michoacán & $50 \%$ & $50 \%$ & $50 \%$ & $50 \%$ \\
\hline 11 Morelos & $50 \%$ & $50 \%$ & $50 \%$ & $50 \%$ \\
\hline 12 Nuevo León & $50 \%$ & $50 \%$ & $50 \%$ & $50 \%$ \\
\hline 13 Querétaro & $50 \%$ & $50 \%$ & $50 \%$ & $50 \%$ \\
\hline 14 San Luis Potosí & $50 \%$ & $50 \%$ & $50 \%$ & $50 \%$ \\
\hline 15 Sonora & $50 \%$ & $50 \%$ & $50 \%$ & $50 \%$ \\
\hline 16 Tabasco & $50 \%$ & $50 \%$ & $50 \%$ & $50 \%$ \\
\hline
\end{tabular}


Esta obra forma parte del acervo de la Biblioteca Jurídica Virtual del Instituto de Investigaciones Jurídicas de la UNAM www.juridicas.unam. $\mathrm{mx}$

https://biblio.juridicas.unam.mx/bjv

https://revistas.juridicas.unam.mx/

DOI: http://dx.doi.org/10.22201/iij_.24487910e_2015.7.10087

\begin{tabular}{|l|l|l|l|l|}
\hline 17 Tlaxcala & $50 \%$ & $50 \%$ & $50 \%$ & $50 \%$ \\
\hline
\end{tabular}

En el ámbito estrictamente municipal:

\begin{tabular}{|c|c|c|}
\hline \multicolumn{3}{|c|}{$\begin{array}{l}\text { Principio paritario-igualitario en materia política- } \\
\text { electoral ayuntamientos }\end{array}$} \\
\hline \multirow[b]{2}{*}{ Entidad federativa } & Constitución & $\begin{array}{l}\text { Legislación } \\
\text { electoral }\end{array}$ \\
\hline & \multicolumn{2}{|l|}{ Ayuntamiento } \\
\hline 1 Baja California Sur & $50 \%$ & $50 \%$ \\
\hline 2 Campeche & $50 \%$ & $50 \%$ \\
\hline 3 Chiapas & $50 \%$ & $50 \%$ \\
\hline 4 Colima & $50 \%$ & $50 \%$ \\
\hline 5 Distrito Federal & $50 \%$ & $50 \%$ \\
\hline 6 Estado de México & $50 \%$ & $50 \%$ \\
\hline 7 Guanajuato & $50 \%$ & $50 \%$ \\
\hline 8 Guerrero & $50 \%$ & $50 \%$ \\
\hline 9 Jalisco & $50 \%$ & $50 \%$ \\
\hline 10 Michoacán & $50 \%$ & $50 \%$ \\
\hline 11 Morelos & $50 \%$ & $50 \%$ \\
\hline 12 Nuevo León & $50 \%$ & $50 \%$ \\
\hline 13 Querétaro & $50 \%$ & $50 \%$ \\
\hline 14 San Luis Potosí & $50 \%$ & $50 \%$ \\
\hline 15 Sonora & $50 \%$ & $50 \%$ \\
\hline 16 Tabasco & $50 \%$ & $50 \%$ \\
\hline 17 Tlaxcala & $50 \%$ & $50 \%$ \\
\hline
\end{tabular}

Mantienen en sistema de cuotas en la integración de Congresos y Ayuntamientos:

DR (C) 2018. Instituto de Investigaciones Jurídicas, UNAM, https://revistas.juridicas.unam.mx/index.php/derecho-electoral/issue/archive 
Esta obra forma parte del acervo de la Biblioteca Jurídica Virtual del Instituto de Investigaciones Jurídicas de la UNAM www.juridicas.unam.mx https://biblio.juridicas.unam.mx/bjv https://revistas.juridicas.unam.mx/

DOl: http://dx.doi.org/10.22201/iij.24487910e.2015.7.10087

\begin{tabular}{|c|c|c|c|c|c|c|}
\hline \multicolumn{7}{|c|}{$\begin{array}{l}\text { Entidades federativas, ayuntamiento } \\
\qquad y \text { cuotas }\end{array}$} \\
\hline \multirow{3}{*}{ Entidad federativa } & \multirow{2}{*}{\multicolumn{2}{|c|}{\begin{tabular}{|l|} 
Constitución \\
Congreso
\end{tabular}}} & \multicolumn{4}{|c|}{ Legislación electoral } \\
\hline & & & \multirow[t]{2}{*}{ Ayunt. } & \multicolumn{2}{|c|}{ Congreso } & \multirow[t]{2}{*}{ Ayunt. } \\
\hline & MR & RP & & MR & RP & \\
\hline 1 Aguascalientes & & & & $40 \%$ & $40 \%$ & $40 \%$ \\
\hline 2 Baja California & & & & $40 \%$ & $25 \%$ & $40 \%$ \\
\hline 3 Chihuahua & & $50 \%$ & & $50 \%$ & $50 \%$ & $50 \%$ \\
\hline 4 Coahuila & & & & $50 \%$ & $50 \%$ & $50 \%$ \\
\hline 5 Durango & $50 \%$ & $50 \%$ & $50 \%$ & $30 \%$ & $30 \%$ & \\
\hline 6 Hidalgo & $50 \%$ & $50 \%$ & & $30 \%$ & $30 \%$ & $30 \%$ \\
\hline 7 Nayarit & & & & $40 \%$ & $50 \%$ & $40 / 50 \%$ \\
\hline 8 Oaxaca & & & & $40 \%$ & $40 \%$ & $40 \%$ \\
\hline 9 Puebla & $50 \%$ & $50 \%$ & $50 \%$ & $50 \%$ & $50 \%$ & $30 \%$ \\
\hline 10 Quintana Roo & $40 \%$ & $40 \%$ & $40 \%$ & $40 \%$ & $40 \%$ & $40 \%$ \\
\hline 11 Sinaloa & & & & $40 \%$ & $40 \%$ & $40 \%$ \\
\hline 12 Tamaulipas & $50 \%$ & $50 \%$ & $50 \%$ & $40 \%$ & $30 \%$ & $40 \%$ \\
\hline 13 Veracruz & & & & $30 \%$ & $30 \%$ & $30 \%$ \\
\hline 14 Yucatán & $50 \%$ & $50 \%$ & & $50 \%$ & $50 \%$ & $30 \%$ \\
\hline 15 Zacatecas & & & & $40 \%$ & $40 \%$ & $40 \%$ \\
\hline
\end{tabular}

\section{A manera de conclusión: las ausencias en la reforma constitucional y legal 2014}

El desarrollo precedente nos permite inferir que la reforma constitucional y legal evidencia el paso firme hacia la igualdad material que habrá de verse sumada a las reformas plenas a los estatutos de los partidos políticos que reflejen el principio paritario 50-50. 
Esta obra forma parte del acervo de la Biblioteca Jurídica Virtual del Instituto de Investigaciones Jurídicas de la UNAM

Pero hay insuficiencias en el marco normativo y en la cultura de la inclusión, y la paridad, como son:

1) Al interior de los propios partidos políticos el principio igualitario en la selección de las precandidaturas y en la integración de los órganos de dirección y decisión y, consecuentemente, la revisión de la LGIPE en lo tocante.

2) Aplicación del baremo 50-50, con principio de alternancia en la integración de los órganos administrativos y jurisdiccionales electorales nacional y de las entidades federativas.

3) La extensividad a los cargos de RP y MR para la integración de los ayuntamientos.

A lo anterior se ha de sumar una intensa actividad al interior de los partidos políticos para desterrar las malas prácticas en la designación de las mujeres en distritos que saben, de antemano, están perdidos así como la intensa labor de formación de lideresas a la que están obligados, el reforzamiento de mecanismos de transparencia, rendición de cuentas y responsabilidades ante el incumplimiento de la paridad, como del $2 \%$ de financiamiento destinado a la capacitación y formación de liderazgo femenino.

La imperiosa necesidad de las instituciones que apoyan el adelanto de las mujeres queden sometidas a una férrea auditoría respecto del uso y destino de los recursos destinados a la consolidación de la paridad en México, tanto en lo orgánico representativo de lo político-electoral como de la paulatina progresividad en otros ámbitos de la vida nacional.

\section{FUENTES CONSULTADAS}

ANTONOPOULOS, Rania, “Estado, diferencia, diversidad: buscando un camino con mayor democracia e igualdad de género", Democracia. Estado. Ciudadanía. Hacia un Estado de y para la democracia en América Latina, Lima, PNUD, 2007.

Benítez Manaut, Raúl, "La crisis de seguridad en México", Nueva Sociedad Núm. 220, México, marzo-abril de 2009, http://nuso.org/upload/articulos/3601_1.pdf

CAMACHO, Carlos, "Propuesta de un modelo de comunicación masiva para la construcción de ciudadanía en América Latina", Razón y Palabra $N^{\circ} 74$, México, Tecnológico de Monterrey, octubre-noviembre de 2003, http://razonypalabra.org.mx/anteriores/n35/ccamacho.htm/.

CANo, Gabriela, “Las feministas en campaña”, Debate Feminista, México, núm.4, 1991. 
Esta obra forma parte del acervo de la Biblioteca Jurídica Virtual del Instituto de Investigaciones Jurídicas de la UNAM www.juridicas.unam.mx

DOI: http://dx.doi.org/10.22201/iij.24487910e.2015.7.10087

Gepall, Género y Partidos Políticos en América Latina, Banco Interamericano de Desarrollo, http://www6.iadb.org/Research/Geppal/tabsdataParty.cfm?language=Spanish\&countr $y=M E X \&$ parties $=57 \&$ categor $=1 \&$ pagref $=1$

Declaración Americana de los Derechos y Deberes del Hombre, Bogotá, 1948.

Diario Oficial de la Federación del 31 de diciembre de 1974.

Diario Oficial de la Federación del 13 de noviembre de 2007.

Diario Oficial de la Federación del 14 de enero de 2008.

Diario Oficial de la Federación del 7 de julio de 2011.

Diario Oficial de la Federación del 8 de septiembre de 2008.

Diario Oficial de la Federación del 14 de enero de 2001.

Diario Oficial de la Federación del 14 de enero de 2008.

Diario Oficial de la Federación del 21 de diciembre de 2009.

DIETZ, Mary G., El contexto es lo que cuenta: feminismo y teorías de la ciudadanía, Debate feminista, 2001.

Género y Democracia, México, IFE, 2011, http://genero.ife.org.mx/genero_partidos.html.

Gómez MAGANDA, Margarita, Mujer y política: la lucha por la igualdad en México, De igual a igual, México, Segob-Programa Nacional de la Mujer-Coordinación General de la Comisión Nacional de la Mujer, 2000.

Hacia la construcción de un Estado de ciudadanía, Seminario internacional Estado, democracia y construcción de ciudadanía en América Latina, México, PNUD, Unión Europea, Colegio de México, Centro de Investigación y Docencia Económica, Fundación Este País, 2008, http://www.gobernabilidaddemocraticapnud.org/archivos/1254759092Debates\%20Se minario\%20Democracia\%20AL.pdf

Hernández, María del Pilar, "Avances de los derechos humanos de la mujer en México. Hacia una pedagogía de la igualdad en la diferencia", Revista Latinoamericana de Derecho Social, México, núm. 10, enero-junio de 2010.

—_—, “La participación de la mujer en el ámbito público: economía, administración y 
Esta obra forma parte del acervo de la Biblioteca Jurídica Virtual del Instituto de Investigaciones Jurídicas de la UNAM www.juridicas.unam.mx

política", Boletín Mexicano de Derecho Comparado, México, núm. 101, mayo-agosto de 2001.

Instituto Federal Electoral, Estudio muestral de participación ciudadana en las elecciones 2009, www.ife.org.mx.

LAGARDE, Marcela, Género y feminismo. Desarrollo humano y democracia, Madrid, Horas y Horas, 1997.

LEVITSKY, Steven y WOLFSON, Leandro, “Del sindicalismo al clientelismo. La transformación de los vínculos partido-sindicatos en el peronismo, 1983-1999", Desarrollo Económico, vol. 44, núm. 173, junio.

MoufFe, Chantal, Feminismo, ciudadanía y política democrática radical, Debate feminista, 2001.

MUNCK, Gerardo L., “La política democrática en América Latina, contribuciones de una perspectiva institucional", Política y Gobierno, México, núm.2, 2004.

Nuestra Democracia, Programa de Naciones Unidas para el Desarrollo, Secretaría General de Naciones Unidas, México, Fondo de Cultura Económica, 2011.

O'DonnelL, Guillermo, "Delegative democracy", Journal of Democracy Number 1, enero de 1994.

PeÑa Molina, Blanca Olivia, La paridad de género en candidaturas a cargo de elección popular: avances y retos en los congresos estatales y ayuntamientos en México,

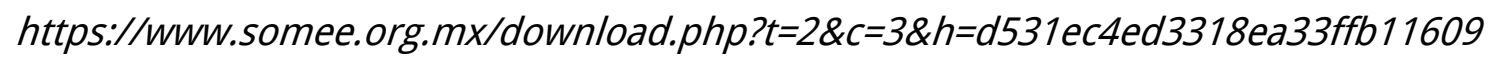
$26 e 28748 b c b b 8 f e$

- - - "Paridad de género en México: anverso y reverso", condistintosasentos. Investigación y reflexión sobre América Latina, http://www.condistintosacentos.com/paridad-de-genero-en-mexico-anverso-yreversol

Ríos TOVAR, Marcela, Género, ciudadanía y democracia, en Democracia. Estado. Ciudadanía. Hacia un Estado de y para la democracia en América Latina, Lima, PNUD, 2007.

SÁnchez Olvera, Alma Rosa, "El feminismo en la construcción de la ciudadanía de las mujeres en México", Revista Itinerario de las Miradas, México, núm. 63, abril de 2006. 
Esta obra forma parte del acervo de la Biblioteca Jurídica Virtual del Instituto de Investigaciones Jurídicas de la UNAM www.juridicas.unam.mx

VASAK, Karel, Human Rights: A Thirty-Year Struggle: the Sustained Efforts to give Force of Law to the Universal Declaration of Human Rights, Paris, UNESCO, Courier 30:11, United Nations Educational, Scientific and Cultural Organization, 1977.

ZAREMBerG, Gisela, Mujeres, votos y asistencia social en el México priista y la Argentina peronista, México, Flacso, 2009. 